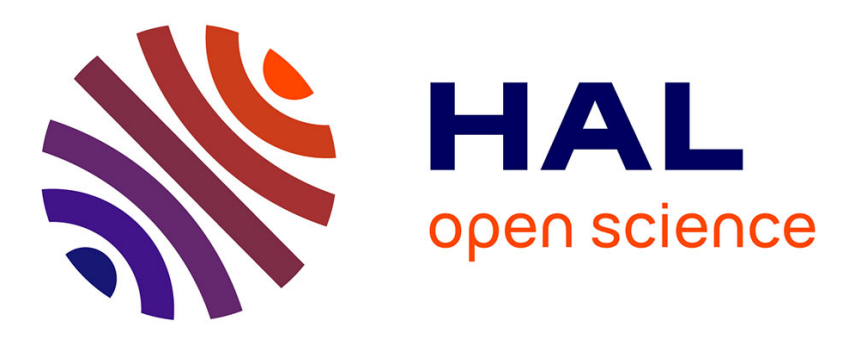

\title{
Elaboration and sintering behavior of a laminar ceramic-ceramic material
}

Pierre Letullier, Jean-Marc Heintz

\section{To cite this version:}

Pierre Letullier, Jean-Marc Heintz. Elaboration and sintering behavior of a laminar ceramicceramic material. Journal de Physique IV Proceedings, 1993, 03 (C7), pp.C7-1471-C7-1475. 10.1051/jp4:19937230 . jpa-00251867

\section{HAL Id: jpa-00251867 https://hal.science/jpa-00251867}

Submitted on 1 Jan 1993

HAL is a multi-disciplinary open access archive for the deposit and dissemination of scientific research documents, whether they are published or not. The documents may come from teaching and research institutions in France or abroad, or from public or private research centers.
L'archive ouverte pluridisciplinaire HAL, est destinée au dépôt et à la diffusion de documents scientifiques de niveau recherche, publiés ou non, émanant des établissements d'enseignement et de recherche français ou étrangers, des laboratoires publics ou privés. 


\title{
Elaboration and sintering behavior of a laminar ceramic-ceramic material
}

\author{
P. LETULLIER and J.M. HEINTZ
}

Laboratoire de Chimie du Solide du CNRS, 351 Cours de la Libération, 33405 Talence cedex, France

\begin{abstract}
The elaboration of a new type of laminar ceramic-ceramic material is presented. The problem of constrained sintering that follows is adressed : densification kinetics of free samples and constrained powder films are studied and analysed. A microstructural model where the "pore size" evolution is considered, has been developed. A good description of the densification kinetics is then obtained. The lower sintering rate of the constrained layer is mainly due to pore coalescence phenomena.
\end{abstract}

\section{INTRODUCTION}

This paper is devoted to the study of the sintering behavior of alumina powders and especially to powder films constrained by dense ceramic substrates. Many research works have been made to design ceramic materials with high toughness, i.e. flaw or crack tolerant. Laminar ceramics appear as a good opportunity to enhance structural reliability of materials (1). Structures composed of a stacking of layers of different compositions are actively developed (2-5). For our part, we are currently working on materials consisting of dense ceramic sheets bonded with porous ceramic layers. The dense ceramic substrates provide high strengh while the porous layers are used to avoid catastrophic propagation of the cracks. A powder film is deposited between two substrates and the resulting material is sintered without any external pressure. The shrinkage of the powder film is actually constrained by the two substrates and can only occur in the zOz' direction. This paper is focused on the densification behavior of the constrained layer since the densification rate is altered by the xOy constraint. Scherer and Garino (6) originally proposed a constrained-film sintering model. However, alumina constrained sintering (solid state diffusion) is not well described in this approach (7).

We propose then a microstructural model where the "pore size" evolution is considered. It allows to describe the densification kinetics related to the predominant diffusion mechanism. The lower densification rate, observed in the case of a constrained sintering, can then be explained on the basis of the "pore size" evolution. 


\section{ELABORATION PROCESS}

\section{II.1. Starting materials}

Alumina powders were high purity powders (Baikowski CR 15, $99.99 \%$ ) and the mean grain size, estimated from SEM measurements, was $0.28 \mu \mathrm{m} . \mathrm{Al}_{2} \mathrm{O}_{3}$ substrates were polycristalline materials (Coors $96 \%$ ) or non oriented monocristalline substrates for the dilatometric studies. The thickness of the substrates was $635 \mu \mathrm{m}$.

\section{II.2. Elaboration process}

An $\mathrm{Al}_{2} \mathrm{O}_{3}$ dispersed slurry, $10 \mathrm{w}$. \%, is prepared at $\mathrm{pH}=4$ with an addition of $1 \mathrm{w} . \%$ of polyvinylalcohol. The slurry is then sprayed on a substrate. A uniform powder layer can be obtained and its thickness (between 70 and $200 \mu \mathrm{m}$ ) is controlled using gas flow and/or spraying time parameters. The sandwich material is realized by pressing together 2 or more substrate-film parts at $65 \mathrm{MPa}$. Sintering is then carried out at $1400^{\circ} \mathrm{C}$ in air without any applied pressure.

\section{SINTERING BEHAVIOR}

\section{II.1. Experimental procedure}

The densification behavior of two type of samples was investigated : non constrained pellets and sandwiched powder layers. Free sintered samples were initially 6 or $8 \mathrm{~mm}$ diameter pellets. Their green relative density was 0.44 . Constrained specimen were powder films deposited between saphire substrates. The green relative density of the powder was also 0.44 . Densification kinetics were obtained from dilatometric measurements. Some individual data were obtained from weight and dimension measurements to check relative density values. Grain size were measured from SEM micrographs of fractured specimen. Equivalent pore size were deduced from image analysis measurements on the same SEM micrographs.

\section{III.2. Results}

The evolution of the relative density of the free and constrained samples versus sintering time is given in Fig. 1. Densities of the constrained film are always smaller than densities of the pellets. The sintering rate difference is especially important for sintering time less than $1 \mathrm{~h}$. Afterwards, densification rates of both type of samples become low and the density difference observed during the first hour of sintering is maintained.

In the same way, the respective evolution of grain size $(G)$ versus sintering time is illustrated in Fig. 2. It shows a smaller grain size in the constrained ceramic film for a given sintering time. This

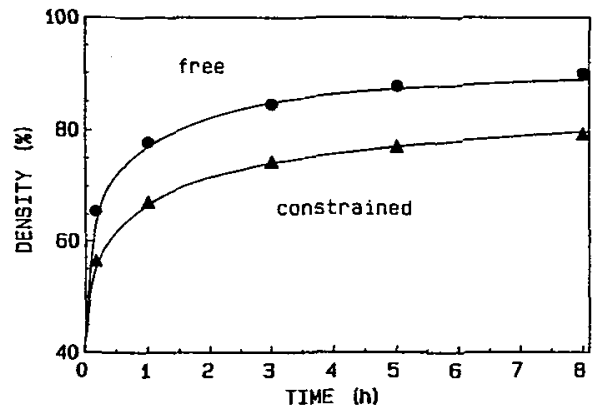

Fig. 1. - Evolution of relative density versus sintering time of free sintered samples and constrained powder layers. observation is even true for a given relative density. 
Solid state diffusion model (8) predicts a densification kinetics inversely proportional to a power of the grain size. In our case, after a $5 \mathrm{~h}$. sintering time, the densification kinetics of the two type of samples are very low and almost the same when the grain size is notably different. Moreover, for less than $5 \mathrm{~h}$. the densification rate of the constrained film is slower than for the free specimen although the grain size in the film is smaller. The logic of the Coble's model do not seem to be respected. We propose then an improvement of the solid state sintering model in order to be able to describe correctly the densification behavior of the powder layer.

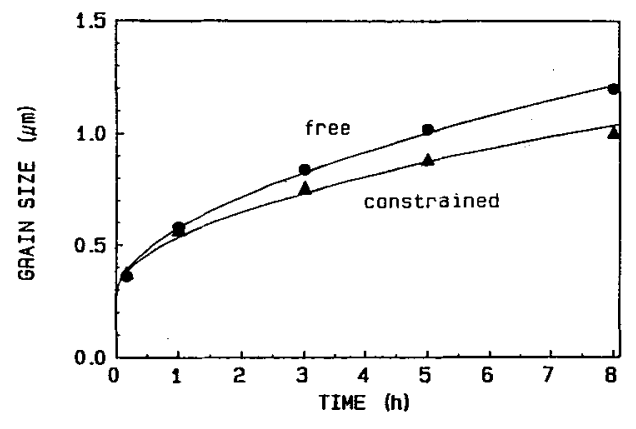

Fig. 2. - Evolution of grain size versus sintering time of free sintered samples and constrained powder layers.

\section{III.3. Theory}

The microstructure of a ceramic can be considered as the sum of numerous elementary cells. The basic geometry element has been chosen to be the well known tetrakaidecahedron. Each unit cell (tetrakaidecahedron) actually contain one grain, size G, and its associated porosity, modelized by a cylinder located along the edge of the polyhedron (radius $\mathrm{r}_{\mathrm{p}}$ ). Contrary to the Coble's model where the number of pores is assumed to be constant during the intermediate stage of the densification, we introduce a parameter "a" to describe both the evolution of the "number of pores" (separation of a unique cylindrical pore in many cylindrical pores) and their size. It means that only a fraction of the total length of the polyhedron edge can be occupied by a pore. " $a$ " is then defined as the ratio of the occupied edge length on the total length.

The porous volume per grain can then be expressed as :

$$
V_{p}=a \cdot\left(36 \cdot \pi \cdot r_{p}^{2} \cdot l_{p}\right) / 3
$$

On the other hand, $V_{p}=(1-\rho) \cdot G^{3} / 2$ and the edge length of the polyhedron is $: l_{p}=G / 2 . \sqrt{2}$. Then

$$
a=\frac{\sqrt{2} \cdot G^{2}}{12 \cdot \pi \cdot r_{p}^{2}} \cdot(1-p)
$$

The decrease of "a" with sintering time is significant of the elimination of the interconnected porosity and its transformation into isolated porosity.

\section{III.4. Densification rate}

The flux of atoms per unit length arriving in a cylindrical pore has been defined by many authors (9-11). Then, for a unit cell and considering that the diffusion is controlled by grain boundary (diffusion field limited by the thickness $\delta$ of the grain boundary) the total flux can be expressed as :

$$
\mathrm{J}=36 \cdot \mathrm{a} \cdot \mathrm{l}_{\mathrm{p}} \cdot \operatorname{cste} \cdot \frac{\mathrm{D}_{\mathrm{s}} \cdot \delta \cdot \gamma}{\mathrm{k}_{\mathrm{B}} \mathrm{T} \cdot \mathrm{G} \cdot \mathrm{r}_{\mathrm{p}}}
$$


The variation of the porous volume per cell is given by : $\mathrm{dV} / \mathrm{dt}=\mathrm{J} . \Omega$ ( $\Omega$ : atomic volume) Then, considering that $\dot{\rho} / \rho=-\dot{V}_{p} / V_{T}$ where $\dot{V}_{p}$ is the variation of the porous volume and $V_{T}$ the total volume of the sample, the densification rate can be written as a function of "a", $G$ and $\rho$ :

$$
\dot{\rho}=\operatorname{cste} \cdot \frac{\mathrm{a}^{3 / 2}}{\mathrm{G}^{4} \cdot \sqrt{(1-\rho)}}
$$

\section{DISCUSSION}

Experimental values of "a", $G$ and $\rho$ for free sintered samples, allow to plot the curve $\log \left[\dot{\rho} . \sqrt{(1-\rho)} / \mathrm{a}^{3 / 2}\right]$ as a function of $-\log (\mathrm{G})$ (Fig. 3). It appears clearly that the experimental data are well aligned. The slope of the straight line should represent the exponent of $G$ in relation (4). A value of 4 is actually found, which must be the case for a grain boundary solid state diffusion mechanism.

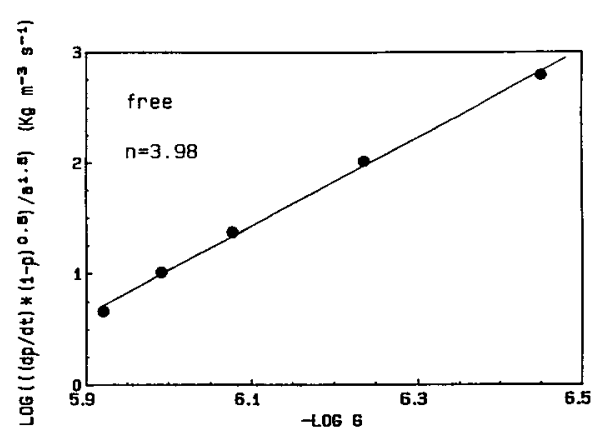

Fig. 3. - Experimental values of $\log \left[\dot{\rho} . V(1-\rho) / a^{3 / 2}\right]$ as a function of $-\log (G)$ for a free sintered sample.

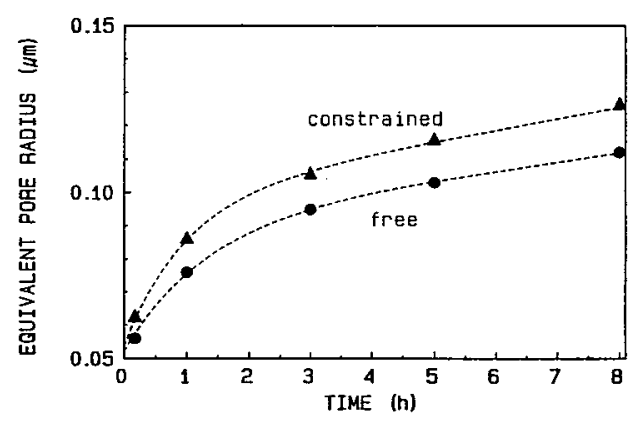

Fig.4. - "Pore size" evolution versus sintering time of free sintered samples and constrained powder layers.

Then, the characterization of the sintering behavior of the constrained ceramic film is obtained by testing our model with the constrained experimental data. Like in the previous case, the fit with a grain boundary diffusion model is excellent (slope $=3.97$ ). The predominant diffusion mechanism must be the same since the alumina powder used in the two type of samples was the same and since the substrates were also pure alumina. The difference in the sintering behavior is then related to the porosity evolution. The constraint due to the dense substrates leads to an increase of the average pore size in the powder layer, as it can been seen in Fig. 4. Mobility of grains, close to the substrates, is highly reduced due to their attachment to the substrate. Therefore, sintering can only occur by grain motion from the center of the layer to the substrates, leading to pore opening (coalescence) around inhomogeneities initially present in the green powder film. Since the diffusion flux is inversely proportional to the size of the pores, the densification rate is reduced. This effect is clearly shown when "a" is written as a function of $r_{p}$ and the densification rate becomes :

$$
\dot{\rho}=\operatorname{cste} \cdot \frac{(1-\rho)}{G \cdot r_{p}{ }^{3}}
$$




\section{CONCLUSION}

A solid state diffusion mechanism has been proposed. It involves a parameter "a" which describes explicitely the evolution of the porosity during sintering. A better description of the evolution of the ceramic microstructure during sintering using $\mathrm{G}$ and "a" is obtained. Sintering of the studied alumina powder is controlled by a grain boundary diffusion mechanism. The specific behavior of the constrained ceramic film appears related to the evolution of the porosity as shown by tha "a" parameter. Coalescence of pores in the early stage of the sintering process leads to a significant reduction of the densification kinetics.

\section{REFERENCES}

[1] HARMER M.P., CHAN H.M. and MILLER G.A., J. Am. Ceram. Soc. 75 (1992) 1715

[2] BOCH P., CHARTIER T. and HUTTEPAIN M., J. Am. Ceram. Soc. 69 (1986) 191

[3] TAKEBE H. and MORINAGA K., J. Ceram. Soc. Jpn. Inter. 96 (1988) 1122

[4] RUSSO C.J., HARMER M.P., CHAN H.M. and MILLER G.A., J. Am. Ceram. Soc. 75 (1992) 3396

[5] FOLSOM C.A., ZOK F.W., LANGE F.F. and MARSHALL D.B., J. Am. Ceram. Soc. 75 (1992) 2969

[6] GARINO T.J. and BOWEN H.K., J. Am. Ceram. Soc. 73 (1990) 251

[7] SCHERER G.W. and GARINO T.J., J. Am. Ceram. Soc. 68 (1985) 216

[8] COBLE R.L., J. Appl. Phys. 32 (1961) 787

[9] HERRING C., in "The physics of powder metallurgy" Ed. W.E. Kingston, McGraw-Hill, New York (1951) p 143

[10] CANNON R.M. and CARTER W.C., J. Am. Ceram. Soc. 72 (1989) 1550

[11] HANSEN J.D., RUSIN R.P., TENG M-H and JOHNSON D.L., J. Am. Ceram. Soc. 75 (1992) 1129 